\title{
Pedagogical Conditions as a Subject for Scientific Research in Ukraine: Nature, Structure, Characteristics, and Functions
}

\author{
DMITRENKO Tamara ${ }^{1}$, LAVRYK Tatjana ${ }^{2, b^{*}}$, YARESKO Ekaterina ${ }^{3}$ \\ ${ }^{1}$ Kherson State University, Ukraine \\ ${ }^{2}$ Sumy State University, Ukraine \\ ${ }^{3}$ Kharkiv State Pedagogic University Named After G. Skovoroda, Ukraine \\ bemail: metodist@dl.sumdu.edu.ua
}

Keywords: pedagogical conditions, the subject of research, pedagogical system, optimization, pedagogical process.

\begin{abstract}
The article describes the essence of the pedagogical conditions as the subject of scientific research in Ukraine. The authors consider the relationship of pedagogical conditions with the problem of the study, with the means of its solutions, and identify the binary nature of the pedagogical conditions. The article discusses features of pedagogical conditions: universality, instrumentality, addressing study problems, continuity, hierarchy, integration, adaptability. The authors determine the functions of pedagogical conditions: to implement the connection of the optimization theory with practice; to be an instrument for solving problems in the study; to be a means of integration of the scientific research; to influence the technology of the processes in the educational system in order to increase efficiency.
\end{abstract}

\section{Introduction}

The priority task of higher education is to produce a competent professional who can work effectively outside the educational environment and resolve typical problems arising in professional activity. The implementation of the tasks requires teachers to create appropriate conditions which contribute to achieving these objectives. The research analysis on pedagogy shows that a developed variety of pedagogical conditions aimed at solving specific problems, for example, the formation of a professional orientation in the student's personality, the management of its independent study, research and others. We believe that the issues related to the definition of the essence, structure, characteristics and functions of pedagogical conditions, their role in the study as well as in the practice of a high school teacher are relevant but insufficiently studied.

The aim of the article is to examine the nature, structure, characteristics, and functions of pedagogical conditions in scientific research.

The philosophical interpretation of the concept of "condition" is related to the ratio of the object to the phenomena, without which it could not exist [1, p. 98]. The set of specific conditions regarding the object or phenomenon creates an environment in which they arise, exist and develop.

Under the "pedagogical conditions", the scientists consider the factors that are in the process of learning and affect the educational activity and its results [2, p. 95].

An analysis of pedagogical literature shows that the conditions are associated with the process and the system. Therefore, we assume that there is a genus-species relation: pedagogical condition is a factor which affects the educational process, educational system, and causes the necessary changes.

\section{Discussion and results}

Analysis of educational research has shown that pedagogical conditions are the subject of research by Ukrainian scientists $[3,4,5,6,7,8,9]$. In the above studies, the pedagogical conditions have a clear focus - to solve a given problem. For example, in the thesis of T.V. Lavryk on "Pedagogical conditions for optimizing the system of distance learning of bachelors degree in 
"System sciences and cybernetics" at the university ", the optimization of the distance learning system is a problem, and pedagogical conditions are aimed at its solution.

The structure of the scientific bases of T.V. Lavryk's research includes the following components:

1) the relevance of the research topic;

2) the analysis of the factors that affect the educational system: objective - from the external environment; subjective - reaction of the system subjects to external influence; personal - the impact of the characteristics of the subjects on the system functioning; human - the role of a human as the subject of the system who makes the decision;

3) the identification and analysis of the contradictions that arise under the influence of the factors;

4) justification of the research problem and topic;

5) the wording of goals, tasks, an object, a subject, restrictions;

6) the development of criteria to optimize the educational system of distance learning Bachelors degree;

7) justification of pedagogical conditions for solving the problem of research;

8) the use of pedagogical conditions for the development of the educational system components.

The components of the structure of scientific research bases can be represented as a series connection of three groups: 1-6, 7, and 8. An analysis of the resulting compound shows that the central component is the seventh which justifies pedagogical conditions for solving the optimization problem of the pedagogical system; the first six components are involved in their development, and the eighth one performs the function of communication of theory-based teaching environment with practical activities of a teacher in a high school.

Let us reveal the essence of some of the components of scientific bases on the example of T.V. Lavryk's study. The main contradiction arises under the influence of the subjective factor, namely, between the need for science-based optimization of the distance learning Bachelors degree system and the absence of clearly justified conditions for that optimization.

The following pedagogical conditions have been determined to reduce the action of the subjective factor:

1) Adaptation of students to the conditions of distance learning and the scope of future professional activity with the help of distance learning courses as a means of organization and management.

2) Organization of independent informative activity for distance learning students with the help of the workbook in the process of training.

3) Provision of bachelor basic study through a set of disciplines that make up the theoretical bases of computer science [9].

Thus, pedagogical conditions are the subject of the study as they address the problem of optimizing the educational system, are justified by the components of the scientific research unit, and affect the components of the educational system in accordance with the criteria and constraints.

Figure 1 is a diagram of the implementation of the pedagogical conditions for optimizing the system of distance learning of bachelors degree in "System sciences and cybernetics" at the University. Two groups of features - the pedagogical system of distance learning and training bachelors - define the optimization criteria (ability to self-organization and self-management, the quality of knowledge and skills in the disciplines of the professional cycle) and constraints - the duration of the student's work at the computer with teaching materials for the discipline.

Pedagogical conditions of optimization are realized through the technology of distance learning bachelors that includes:

- A Goal - successful adaptation of students to the conditions of distance learning and future careers, and more efficient vocational training;

- Principles (didactic and specific); 


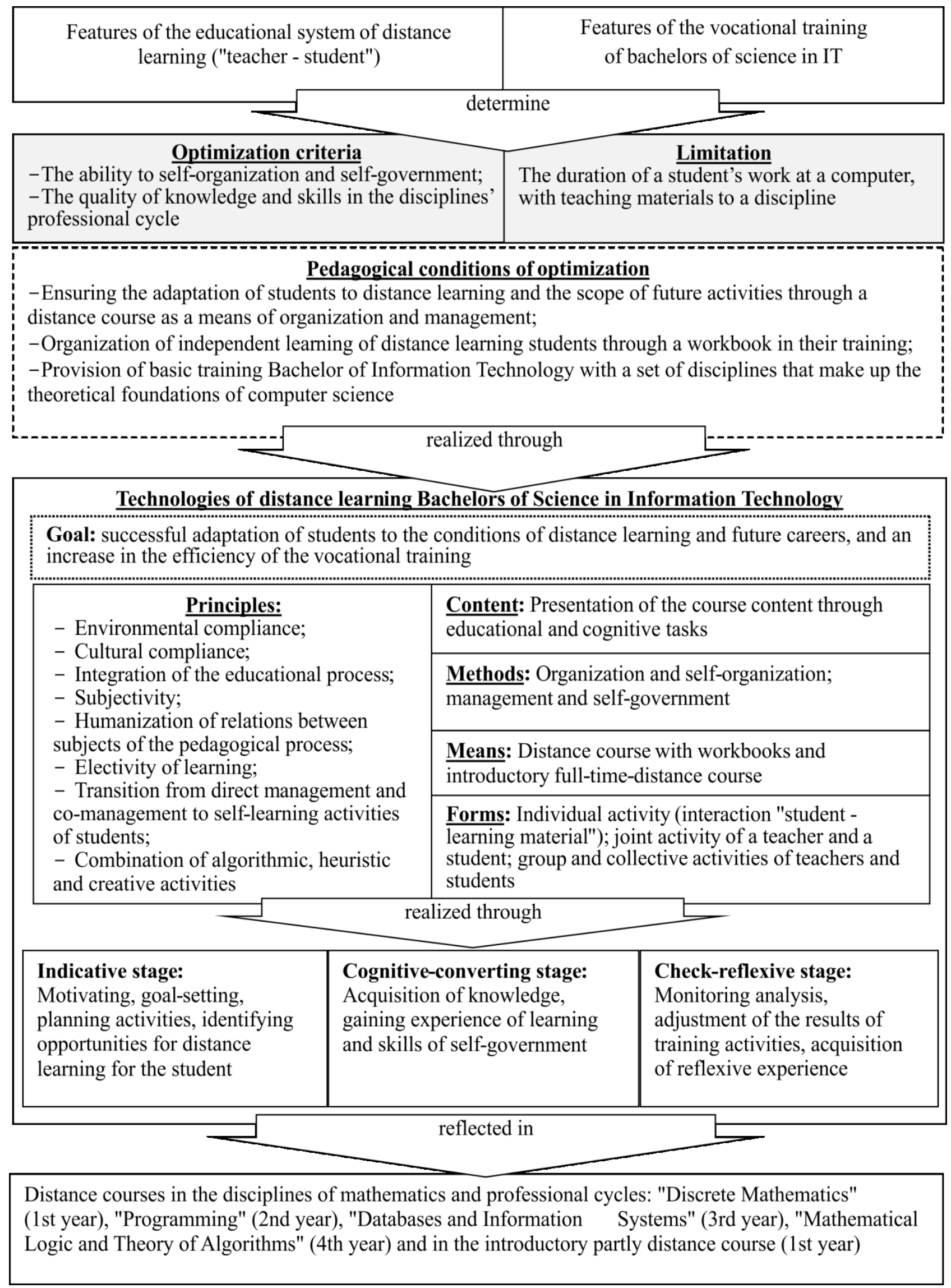

Figure 1. Diagram of pedagogical conditions for optimizing the system of distance learning 
- Components of the educational system of distance learning (content, methods, means, forms of activity);

- Stages: indicative (backbone factor - organization), cognitive and conversion (backbone factor - management), and control and reflexive (backbone factor - communication).

The components of the technology are reflected in distance courses in the disciplines of mathematics and professional cycles: "Discrete Mathematics" (1 year), "Programming" (2nd year), "Databases and Information Systems" (3rd year), "Mathematical Logic and Theory of Algorithms" (4th year) and in the introductory full-time-distance course (1st year).

Let us consider individual elements of the diagram (Fig. 1). Thus, the characteristics of the educational system of distance learning are featured by their components: the objectives, principles, contents, methods, means, forms of activity, subjects (teachers, students). Structural analysis of the above features demonstrates that each of them has two aspects: the first one shows the matter to be decided, and the second one gives the key to its solution (Table 1). For example, the objectives, which are defined by the teacher, are invariant with respect to the form of training, but the goal setting by the distance student must be supported by appropriate means and be systematic. Availability of a question and a key to its solution in each particular feature allows the teacher to use them to design the means of management - a distance course with a workbook.

Revealed features of vocational training bachelors in «System sciences and cybernetics», e.g., the prestige of the profession, the need to constantly replenish the knowledge and skills and to have a fundamental knowledge of computer science, led to the conclusion that the exercise of professional activities requires skills of organization and of management.

The bilateral nature of distance learning and training system for bachelors in the specialty has provided justification for criteria optimization which also include two aspects: the students' ability to self-organization and self-government that reflects a peculiarity of distance learning, as well as the quality of knowledge and skills in the disciplines of the professional cycle that characterizes the quality of vocational training.

Analysis of the pedagogical conditions shows that they are binary, that is, they have two sides of the consideration. The one side of each condition is associated with the problems of adaptation of students to the conditions of distance learning and future professional activities, organization of independent informative activity in distance learning, ensuring fundamental training of bachelors. Another side is associated with the means for its solution: the introductory full-time-distance course, distance learning course with a workbook, a set of distance learning courses in the disciplines.

If we combine pedagogical conditions sequentially according to their use to solve the problem, then the principle of continuity will be implemented. The basis of continuity between introductory full-time-remote courses and distance learning courses are skills that allow students to shape their self-organization and self-management skills by solving problems and moving on to other subjects of the curriculum that constitute theoretical foundations of computer science.

The principle of hierarchy, in our opinion, is realized in the process of solving problems. For example, at basic level of hierarchy, we consider the problem of adaptation, without which it is impossible to come to self-organization of cognitive activities, and even more - to ensure basic training of future specialists.

Since the principle of continuity contributes to the formation of professional experience, the principle of hierarchy allows the student to create their attitude to the process.

Let us consider the nature, structure, characteristics and functions of pedagogical conditions of optimization. In modern philosophy, nature means the totality of the essential characteristics and qualities of a thing; the substantial core of self-existence [10, p. 1008].

Analyzing the above pedagogical conditions of optimizing distance learning Bachelors of Science, we note that their main characteristics are: universality, instrumentality, focus on solving problems, hierarchy, continuity, integration, adaptability.

The universality of the pedagogical conditions is aimed at the implementation of the relationship of educational theory and practice. The focus on the theory manifests itself in the fact 
that the basis of pedagogical conditions for optimization is expressed by optimization theory developed by cybernetics (formulation of the problem, methods of optimization, algorithm as a sequence for solving the problem) [11]. The focus on the relationship of the theory and practice is that pedagogical conditions are used to develop the components of the pedagogical system of distance learning according to the criteria and constraints. We believe that the substantial core of pedagogical conditions is their impact on the practice of learning through educational components of the pedagogical system and technology.

Table 1. Features of the educational system of distance learning at the level "Teacher Student"

\begin{tabular}{|c|c|}
\hline $\begin{array}{l}\text { Pedagogical } \\
\text { System } \\
\text { Components }\end{array}$ & Features \\
\hline Objectives & $\begin{array}{l}\text { 1. The objectives of activities that the teacher determines are invariant regarding the } \\
\text { form of study (full, part-time) } \\
\text { 2. Setting goals by the subject of the educational activities (the student) must be } \\
\text { maintained with appropriate means and be on a systematic basis }\end{array}$ \\
\hline Principles & $\begin{array}{l}\text { Classical principles of the educational system are supplemented by specific ones } \\
\text { (motivation, self-control and self-discipline, initial knowledge of the student, } \\
\text { personalization, interactivity, educational feasibility for application of new information } \\
\text { technologies, priority of the pedagogical approach in the design of the educational } \\
\text { process) }\end{array}$ \\
\hline Content & $\begin{array}{l}\text { 1. The content of education is invariant in relation to learning } \\
\text { 2. Development of the course content must match the sequence of stages of the } \\
\text { learning process, each of which provides means of distance learning course }\end{array}$ \\
\hline Methods & $\begin{array}{l}\text { The choice of methods should take into account the peculiarities of distance learning } \\
\text { and focus on those that are aimed at the student's autonomy in learning and intensify } \\
\text { his activities }\end{array}$ \\
\hline Means & $\begin{array}{l}\text { In terms of distance education, to improve the quality perception of the educational } \\
\text { material, it is appropriate to combine such means as electronic (computer educational } \\
\text { systems, video tutorials, laboratory remote workshops, simulators with remote access, } \\
\text { etc.) and paper (textbooks, manuals, guidelines, etc.) }\end{array}$ \\
\hline Forms & $\begin{array}{l}\text { The conventional forms of teaching such as lectures, seminars, laboratory lessons, } \\
\text { quizzes, tests, consultations, and independent work, are adapted to the conditions of } \\
\text { distance learning through methods for their implementation }\end{array}$ \\
\hline $\begin{array}{l}\text { Subject - } \\
\text { a teacher }\end{array}$ & $\begin{array}{l}\text { 1. The functions of the teacher in the system of distance learning become more } \\
\text { diverse: organization and intensification of students' activities, advice and support. } \\
\text { The content of the teacher's work with respect to the design of the lesson, } \\
\text { presentation of teaching materials, planning, coordination of students, consultation, } \\
\text { monitoring the implementation of the tasks, is complicated and requires appropriate } \\
\text { training of the teacher } \\
\text { 2. The means by which the teacher operates (controls, facilitates, initiates) change, } \\
\text { taking into account the characteristics of distance learning }\end{array}$ \\
\hline $\begin{array}{l}\text { Subject - } \\
\text { a student }\end{array}$ & $\begin{array}{l}\text { 1. The need of propaedeutic to prepare students for distance learning. } \\
\text { 2. Results of distance learning are conditioned by the level of motivation, } \\
\text { autonomy, and activity of the students }\end{array}$ \\
\hline
\end{tabular}

The study of the theoretical aspects of the pedagogical conditions allowed the development of the definition: pedagogical conditions of optimization is an interconnected set of essential factors that affect the educational system to achieve its goals in accordance with the optimization criteria and constraints $[9$, p. 8]. 
Instrumental pedagogical conditions are manifested in the fact that they are aimed at solving research problems - optimization of the educational system by changing its components according to the criteria and constraints.

The binary nature of pedagogical conditions is also evident in the fact that, on the one hand, they must be integrated, and on the other hand to become the framework for the integration of scientific research bases.

Adaptability is an important feature of pedagogical conditions which shows the relationship between theory and practice. Pedagogical conditions are a communication link of paradigms, methodological and theoretical bases of research with the pedagogical system of distance learning (object of optimization) on the one hand, and the condition of the educational process on the other.

Reasonable characteristics of pedagogical conditions can define their functions:

- Universality - to implement the function of the relationship between theory and practice;

- Instrumentality -to be a means of solving the optimization problem of pedagogical system for distance learning Bachelors degree;

- Integration - to serve as the integration of scientific research bases;

- Adaptability - to affect the technology to improve the process efficiency of the distance learning university students.

The features of pedagogical conditions as well as their functions are interconnected. For example, the most important function of the relationship between the pedagogical optimization theory of distance learning Bachelors and teaching practice in a higher school is provided by all features of pedagogical conditions, and especially - by the universality and adaptability.

\section{Conclusion}

1. On the basis of scholarly considerations and the results of research on pedagogy, as well as experience of teaching activities at the university, we set a task to optimize the pedagogical system of distance learning bachelors degree in "System sciences and cybernetics". We defined the features of the educational system and specialists' training at the university, and optimization criteria and constraints.

2. Pedagogical conditions aimed at resolving research problems and reasoned by using two groups of features (pedagogical system and training) and the optimization criteria and constraints became the means for optimizing the educational system of distance learning bachelors.

3. It was found that the pedagogical conditions have a binary structure, include a research problem and the way to solve it, and satisfy the principles of hierarchy and continuity which contribute to the formation of professional experience by influencing the motivational sphere of university students.

4. The essence of pedagogical conditions is reflected in the definition as a result of the study of the theoretical aspects: pedagogical conditions of optimization are an interconnected set of necessary factors that affect the educational system to achieve its goals in accordance with the optimization criteria and constraints.

The main characteristics of the pedagogical conditions are:

- universality (focus on the theory and practice); facilities (means for solving the problem of optimizing the educational system of distance learning bachelors);

- focus on solving the optimization problem;

- hierarchy (solving problems in accordance with the levels of the hierarchy: adaptation of students to distance learning, the organization of independent cognitive activity of students, the fundamental training of specialists);

- continuity between the means of the organization and management of students: full-time entry-distance course as a means of organization and management;

- distance learning course with a workbook;

- a set of disciplines containing the theoretical foundations of computer science;

- integrative (focus on the integration of the components of scientific bases of research; 
- adaptability (improves the efficiency of educational process).

The functions of pedagogical conditions were defined in scientific research as:

- to implement communications of optimization theory with practice;

- to be a tool for solving problems in the study;

- be a means of integrating scientific research bases;

- to affect process technologies in pedagogical system in order to increase their efficiency.

\section{References}

[1] E. F. Gubsky, G. V. Korabliova, Philosophical Encyclopedic Dictionary. Moscow, 2007.

[2] V. I. Yevdokimov, L. D. Pokro'eva, Independent work of students: Textbook, Kharkiv, 2004.

[3] V. B. Bakatanova, Psychological and pedagogic conditions of vocational selection of future pedagogical engineers: Abstract of a thesis, Kyiv, 1996.

[4] L. V. Onuchak, Pedagogical conditions for organization of students' self-testing work of economic specialities: Abstract of a thesis, Kyiv, 2002.

[5] O. V. Khmel, Didactic conditions of organization of distance education of students of physics and mathematics departments of pedagogical universities: Abstract of a thesis, Kyiv, 2006.

[6] O. G. Kirilenko, Pedagogical conditions of training teachers of higher technical educational institutions for the organization of distant teaching: Abstract of a thesis, Kharkiv, 2008.

[7] Y. G. Chebakova, Pedagogical conditions of motivation formation to study psychological and pedagogic disciplines of students of higher technical educational establishments: Abstract of a thesis, Vinnitsia, 2011.

[8] E. M. Hrykov, Pedagogical conditions as part of scientific knowledge, The Path of Education. 2 (2011) 11-15.

[9] T. V. Lavryk, Pedagogical conditions of optimization of distance learning bachelors in the field of "System sciences and cybernetics": Abstract of a thesis, Zaporizhzhya, 2013.

[10] A. A. Gritsanova, The Newest Philosophical Dictionary, Minsk, 2003.

[11] V. M. Korshunov, Mathematical Foundations of Cybernetics: Textbook, Moscow, 1987. 